\title{
Zur Pathologie und Therapie des Abortus.
}

\author{
Von \\ Dr. A. Dührssen, \\ Assistenzarzt an der geburtshülflichen Poliklinik der Charité zu Berlin.
}

Die Frage der besten Therapie des Abortus ist eine noch offene; gegenüber den Anhängern der exspectativen Behandlung des Abortus, die sich noch weitaus in der Mehrzahl befinden, befürwortet die Minderheit ein mehr actives Vorgehen.

Ich sage absichtlich ,ein mehr actives Verfahren“, denn auch Fehling ${ }^{1}$ ) und $\mathrm{Schwarz}^{2}$ ), die Anhänger und Verfechter einer activen Behandlung des Abortus, empfehlen bei noch intactem Ei die Tamponade der Scheide. Erst wenn der Eisack geplatzt ist, oder eine mehrfache Tamponade, combinirt mit Irrigationen der Cervix und Einlegen von Quellmitteln in dieselbe, nicht zum Ziele geführt hat, schreiten sie zur Ausräumung des Uterus. Auch darüber sind die Ansichten noch getheilt, wie eine solche Ausräumung des Uterus am besten auszuführen ist: die einen empfehlen hierfür die Cürette, die anderen den Finger als bestes Instrument.

Ist der Abort unvermeidlich geworden, die Ausstossung des Eies nicht mehr aufzuhalten, so ist sicher diejenige Therapie die beste, welche die vollständigste Ausstossung sämmtlicher Eibestandtheile bei möglichster Schonung des mätterlichen Organismus erreicht. Erfüllt aber die exspectative Therapie, d. h. Znwarten und eventuell, bei stärkerer Blutung, heisse Irrigationen und Tamponade, diese Postulate? Ich glaube, nein!

Nach meinen Beobachtungen ist die Retention von Theilen der Decidua vera nach spontan verlaufenem oder mit Tamponade behandeltem Abort nicht die

1) Dieses Archiv, Bd. XIII, S. 222.

2) Sammlung klinischer Vorträge, Nr. 241.

Archiv f. Gynäkologie. Bd. XXXI. Hft. 2. 
A usnahme, sondern die Regel! Diese Retention hat für die Mutter sehr nachtheilige Folgen. Sie führt häufig zu hartnäckigen erschöpfenden Blutungen, sie bildet bei schon zersetztem Ei einen äusserst günstigen Nährboden für die Fäulnisserreger und bedingt oft eine länger dauernde Schädigung der Gesundheit dadurch, dass sich an sie eine Endometritis, die Endometritis post abortum, anschliesst. Die chronische hyperplasirende, mit stärkeren Blutungen verbundene Endometritis leitet sich, wie noch ganz neuerdings Heinricius ${ }^{1}$ ) wieder nachgewiesen hat, in der Mehrzahl der Fälle von einem früheren Abortus her. ${ }^{2}$ )

Abgesehen von der Schädigung des mütterlichen Organismus, welche demselben bei exspectativer Therapie aus der so häufigen Decidua-Retention und ihren Folgen erwächst, so ist auch schon während des Abortus selbst der Blutverlust, den die Mutter erleidet, bei exspectativem Verhalten ein bedeutend grösserer, als wie bei der activen Therapie. Ehe man sich bei exspectativem Verfahren zu heissen oder kalten Irrigationen und zu der Tamponade entschliesst, hat die Frau schon eine ziemliche Quantität Blutes verloren. Da der Effect der Irrigationen ein unsicherer ist, verliert sie bei Anwendung derselben eventuell noch mehr Blut. Auch die Tamponade verhindert durchaus nicht mit Sicherheit jede weitere Blutung. Sehr häufig habe ich in Fällen, in welchen von Aerzten, Hebammen und Praktikanten tamponirt, und zwar fest tamponirt war, hinter den Tampons noch faustgrosse Blutgerinnsel gefunden. Dies ist meiner Meinung nach auch bei völlig sachgemässer Tamponade nicht mit Sicherheit zu vermeiden. Denn ebenso gut, wie man in manchen Fällen das Ei hinter den Tampons in der Scheide vorfindet, kann sich daselbst, falls das Ei durch die Tamponade nicht gelöst wird, eine Blutmenge ansammeln, welche der Grösse des Eies gleichkommt.

Wie verhält es sich dagegen mit dem Blutverlust bei activem

1) Dieses Archiv, Bd. XXVIII, Hft. 1.

2) Ich verstehe daher nicht, wie Küstner (Berliner klinische Wochenschrift 1880, Nr. 3) die Vera nach Abort ruhig im Uterus lassen will. $K$. begründet dies damit, dass die Vera nichts weiter als hypertrophische Uterusschleimhaut sei. Das ist sie allerdings, aber eine Schleimhaut, die normaler Weise abgestossen werden soll. Uebrigens hat K. späterhin seine Ansicht über die Bedeutungslosigkeit der Decidua-Retention geändert. Vgl. dieses Archiv, Bd. XVIII; Centralblatt für Geburtshülfe 1883, S. 53; Beiträge zur Lehre von der Endometritis. Jena 1883. 
Vorgehen? Bei Aborten im engeren Sinne, d. h. bis zum Ende des dritten Monates, ist derselbe ein minimaler, dessen Maximum bei der von mir angewandten Therapie einen Esslöffel Blutes nicht übersteigt. Auch bei der Unterbrechung der Schwangerschaft vom vierten Monat an, die ich, der Eintheilung Gusserow's folgend, als Fehlgeburten bezeichne, kann man, in Chloroformnarkose wenigstens, die Ausräumung des Uterus so rasch vornehmen, dass der Blutverlust in der Regel auch nicht mehr als $50 \mathrm{~g}$ betragen dürfte. Tamponirt man dagegen nach Ausstossung der Frucht bei einer Fehlgeburt im vierten Monat, bei welcher auch Schwarz ${ }^{1}$ ) die Tamponade noch für erlaubt hält, so wird sich stets im Uterus eine viel grössere Menge Blutes ansammeln. Ich habe wenigstens bei Mehrgebärenden in solchen Fällen den schlaffen, atonischen Uterus mehrmals derart mit Blut angefüllt gefunden, dass sein Fundus in Nabelhöhe stand.

Weitere Vortheile der activen Therapie liegen in dem geringeren Blutabgange nach Beendigung des Abortus und der schnelleren und besseren Rückbildung des Uterus.

Durch Besichtigung der Unterlagen habe ich mich überzeugt, dass nach vollständiger Ausräumung des Uterus kein Tropfen Blut mehr fliesst. Am folgenden Tage zeigen die Unterlagen noch eine fleischwasserähnliche Färbung, am dritten Tage ist ein leichtbräunlicher Ausfluss vorhanden, welcher schon am vierten oder spätestens am fünften Tage einem spärlichen gelben Ausflusse Platz macht. Da man nun berechtigt ist, aus der Beschaffenheit des Ausflusses einen Schluss auf die Rückbildung des Uterus zu machen, so glaube ich, mit Fug und Recht die Behauptung aufstellen zu dürfen, dass nach activer Behandlung des Abortus die Rückbildung des Uterus eine schnellere ist, wie nach normaler Geburt und nach exspectativer Behandlung des Abortus. Bei letzterer nämlich ist selbst nach der vollständigen Ausstossung des Eies ein weiterer Abgang von Blut stets vorhanden. ${ }^{2}$ ) Darauf kommt es nach Dohrn ${ }^{3}$ ) zu einem reichlichen Wochenflusse von übelriechender Beschaffenheit, dem einzelne Eihautfetzen beigemischt sind - alles Zeichen einer schlechten Involution, die Dohrn bei der von ihm geübten exspectativen Therapie für eine gewöhnliche Folge des Abortus hält.

1) $1 . \mathrm{c}$.

2) Schröder, Lehrbuch der Geburtshülfe. 8. Aufl. S. 472.

3) Sammlung klinischer Vorträge, Nr. 42. 
Ein weiterer Punkt von schwerwiegender Bedeutung, wenigstens für die arbeitende Klasse der Bevölkerung, liegt in der längeren Dauer des Abortus und des sich anschliessenden Wochenbettes bei exspectativem Verhalten. Macht der Arzt Irrigationen, tamponirt er oder thut er garnichts, so kann es Tage lang dauern, ehe die Ausstossung des Eies erfolgt. Während dieser Zeit muss die Frau das Bett hüten. Auch das Wochenbett dauert wegen der schlechteren Involution des Uterus nach exspectativem Verhalten länger als nach Ausräumung des Uterus. Die Frau muss also noch weitere acht Tage zu Bett liegen, während sie bei activer Therapie schon am fünften Tage aufstehen kann.

Noch mehr zieht sich bei der exspectativen Therapie der Abort in die Länge, wenn die Eihöhle unbemerkt geplatzt ist. Sehr häufg hält man dann das in der Gegend des unteren Eipoles vorhandene festere Blutgerinnsel für die Spitze des unversehrten Eisackes. In solchen Fällen genügen aber meistens sämmtliche Mittel des exspectativen Verfahrens nicht, um auch nur die Ablösung der Placenta von der Uteruswand zu erreichen, und daher schreiten auch die Anhänger der exspectativen Behandlung des Abortes nach geplatztem Eisack zur Entfernung der Eireste. Falls man sich aber bei abwartendem Verhalten in der angedeuteten Weise in der Diagnose irrt, so wird man weder die Sistirung des Abortus, noch die vollkommene Ausstossung der Eireste erreichen.

Berücksichtigt man ferner die Unbequemlichkeit und Schmerzhaftigkeit der Tamponade, die Unruhe der Frau, so lange sie sich nicht von ihrem Schwangerschaftsproducte befreit weiss, gegenüber der Thatsache, dass die active Therapie in kürzester Zeit den Abort beendet, so wird die Wahl der Methode nicht zweifelhaft sein, vorausgesetzt, dass die active Methode keine grösseren Gefahren für Leben und Gesundheit der Frau in sich schliesst, als die exspectative.

Endlich müssen wir bedenken, wie oft die exspectative Therapie wegen Zersetzung des Eies und Fiebers der Mutter nicht durchzuführen ist!

Alle diese Erwägungen, nämlich geringere Blutung während und nach dem Abort, schnellere Rückbildung des Uterus, Vermeidung der Endometritis post abortum, grössere Bequemlichkeit für Patientin und Arzt bei absoluter Ungefährlichkeit haben mich veranlasst, jeden Abort, sobald er nicht mehr aufzuhalten war, durch sofortige Ausräumung des Uterus zu beenden. Das Kri- 
terium für den Zeitpunkt des activen Vorgehens gab im Allgemeinen die Eröffnung des Cervicalkanales. Sobald derselbe für den Finger durchgängig war, nahm ich die Entfernung des Eies vor. In einigen Fällen gab Zersetzung des Eies oder schon länger dauernde erschöpfende Blutung die Indication zu activem Vorgehen, auch bei noch geschlossenem Cervicalkanale. Ebenso nahm ich, falls das Ei bereits geplatzt war, unbekümmert um die Beschaffenheit des Cervicalkanales die sofortige Entleerung des Uterus vor. Die Zahl der Fälle, welche ich in dieser Weise in der geburtshülflichen Poliklinik der Charité behandelt habe, beträgt 122. ") Von diesen starben 2, doch fallen diese Todesfälle, wie ich später auseinandersetzen werde, nicht der Methode zur Last.

Während mein hochverehrter Chef und Lehrer, Herr Geheimrath Professor Dr. Gusserow, dem ich für seine gütige Erlaubniss zur Veröffentlichung der vorliegenden Arbeit meinen besten Dank ausspreche, im Allgemeinen auch für die active Beendigung des unvermeidlich gewordenen Abortus eintritt, so blieb mir doch die specielle Art der Ausführung, wie es bei der Verschiedenheit der Fälle ja auch nicht anders sein konnte, völlig überlassen.

Bei dem Abort im engeren Sinne, d. h. bis zum Ende des dritten Monats, sind Decidua vera und reflexa noch nicht mit einander verwachsen; hier hat also die active Therapie, um den. idealen Verlauf der Spontanausstossung des Eies nachzuahmen, eine doppelte Aufgabe, nämlich die Entfernung des von Placentaranlage und Decidua reflexa umschlossenen Eisackes und die Entfernung der Decidua vera. Diese doppelte Aufgabe fiele in eine zusammen, wenn sich bei Beginn der Uteruscontractionen die Decidua vera von unten nach oben zu allmälig von der Uteruswand ablöste. Dann würde der ins Uteruscavum eingeführte Finger zunächst den etwa noch anhaftenden oberen Theil der Decidua vera und,sodann die Placentaranlage, resp. die schon gebildete Placenta ablösen.

Die Ansicht, dass sich mit dem Beginn der Wehen beim Abort zuerst die Decidua vera und zwar von unten nach oben zu löse, scheint in der That die allgemein angenommene $z u$ sein. Schröder ${ }^{2}$ ) und Spiegelberg ${ }^{3}$ ) sagen es wenigstens in ihren

1) Die Zahl ist mittlerweile auf 150 gestiegen. Die noch hinzugekommenen Fälle sind ganz nach denselben Grundsätzen und mit demselben günstigen Erfolge behandelt worden.

2) $1 . \mathrm{c}$.

3) Spiegelberg-Wien er, Lehrbuch der Geburtshülfe. 1882. 
Lehrbüchern direct; $Z_{w}$ eife ${ }^{1}$ ) drückt sich über diese Frage nicht bestimmt aus. Dohrn's ${ }^{2}$ ) Auslassungen über diesen Gegenstand lassen ebenfalls eine doppelte Deutung zu, doch verdanke ich einer brieflichen Mittheilung dieses meines früheren hochverehrten Chefs die Kenntniss darüber, dass nach seiner Ansicht sich bei Beginn der Uteruscontractionen zuerst die Placentaranlage des Eies und dann die Decidua vera, und zwar von oben nach unten zu, von der Uteruswand ablöst.

Dieselbe Anschauung habe auch ich mir von dem Modus der Loslösung des Eies in den ersten drei Monaten der Schwangerschaft gebildet. Als Beweis für die Richtigkeit dieser Ansicht führe ich Folgendes an: Ist der Cervicalkanal durch die Uteruscontractionen für den Finger durchgängig geworden, so hat man, falls das $\mathrm{Ei}$ noch nicht in die Scheide geboren ist, bei intactem Ei zwei verschiedene Befunde. Entweder dringt der Finger, ohne irgendwo ein Adhärenz zu finden, bis zum Fundus vor und trifft hier eine Adhärenz des Eies, oder das Ei liegt in dem erweiterten Cervicalkanal, und von dem oberen Eipol geht durch den engen inneren Muttermund hindurch ein strangartiges Gebilde in das Uteruscavum hinein. Löst man nun im ersten Falle das Ei an der adhärenten Stelle und befördert es durch den Höning'schen Handgriff heraus, so findet man in der Regel, dass das Ei nur von der Placentaranlage und der Decidua reflexa gebildet wird, dass mithin die ganze Decidua vera im Uterus zurückgeblieben ist. Höchstens hängen einige Fetzen der Vera an dem Eisacke. Geht man dann nochmals mit dem Finger in den Uterus ein, so fühlt sich die Uteruswand allseitig glatt an, und nur im Fundus findet man dem Finger ausweichende, flottirende Fetzen. Das darauf vorgenommene Cürettement fördert die ganze Decidua vera zu Tage.

Dieser Befund lässt keine andere Deutung zu, als dass sich die Decidua vera von allen Eibestandtheilen zuletzt, $u$ nd $\mathrm{z}$ war von oben nach unten zu, von der Uteruswand ablöst. Denn löste sie sich zuerst, und zwar von unten nach oben, so müsste sie an dem Eisacke, welchen der Finger an der Placentarstelle gelöst, vorhanden sein. Es müsste dann ferner Fälle geben, in

1) Lehrbuch der Geburtshülfe. 1887.

2) 1. c. 
welchen sich durch die Wehenthätigkeit etwa nur die untere Hälfte der Decidua vera gelöst hätte und der eindringende Finger noch den oben anhaftenden Theil der Decidua vera bis zum Fundus hinauf vón der Uteruswand abtrennen müsste.

Niemals stösst aber der eingeführte Finger bei noch im Uteruscarum befindlichem $\mathrm{Ei}$ im unteren Theile des Cavum auf irgendwelche Adhärenz, auf irgendwelche flottirenden Fetzen. Vielmehr dringt der Finger, indem er nach innen die glatte, gespannte, von der Reflexa gebildete Oberfläche des Eisackes, nach aussen ebenfalls eine glatte Fläche fühlt, ohne jeden Widerstand bis zum Fundus und findet erst hier eine Adhärenz des Eies. Dies rührt eben daher, dass die Decidua vera der Uteruswand noch fest anhaftet, dass also der Finger nicht, wie es a priori scheint, $z$ wischen Decidua vera und Uteruswand, sondern in dem bis zum Ende des dritten Monats physiologischer Weise vorhandenen Spalt zwischen Decidua vera und Decidua reflexa, natürlich ohne irgendwelchen Widerstand zu finden, bis in die Gegend des Fundus, bis zur Placentarstelle hinaufdringt!

Auch die zweite Reihe von Fällen spricht für die von mir verfochtene Behauptung. Hier liegt das Ei in der Cervix, die Decidua vera dagegen setzt sich als Strang in das Uteruscavum fort. Auch dieser Befund lässt keine andere Deutung zu, als dass sich die Decidua vera von allen Eibestandtheilen zuletzt, und zwar von oben nach unten zu, löst, und dass in diesen Fällen die Lösung des unteren Abschnittes der Decidua vera noch nicht erfolgt ist. Versucht man nämlich hierbei das Ei durch den Höning'schen Handgriff zu exprimiren oder es manuell zu lösen, indem man mit dem Finger möglichst hoch an dem Deciduastrange in die Höhe geht, so wird man sehr häufig die Erfahrung machen, dass der Strang entweder direct am oberen Eipol oder höher hinauf abreisst und somit noch ein Theil der Decidua vera im Uterus zurïckbleibt.

Löste sich die Decidua vera von unten nach oben und dann erst die Placentarstelle, so würde man in einem gewissen Stadium der Austreibung des Eies auch das Ei in der Cervix steckend finden, die Decidua vera wïrde sich ebenfalls als Strang in das Uteruscavum fortsetzen. Allein bei dieser Voraussetzung ist das Ei vollständig gelöst. Es ist daher nicht einzusehen, wie bei der 
Expression oder der manuellen Lösung des Eies ein Theil der Decidua vera oder dieselbe ganz im Uterus festgehalten werden kann.

Allerdings könnte man den angedeuteten Befund noch anders erklären, wenn man annimmt, dass das $\mathrm{Ei}$ durch eine bedeutende Auszerrung der Placentaranlage oder der Decidua reflexa, die sogenannte Cervicalschwangerschaft Rokitansky's, bis in den Cervicalkanal hinunter gelangt sei. Dann bestünde ja der sich ins Cavum uteri hineinerstreckende Strang nicht aus Decidua vera, und der Befund wäre für eine Theorie über die lösung der Decidua vera überhaupt nicht zu verwerthen. Solche Verhältnisse habe ich aber in meinen Fällen nie angetroffen.

Man könnte mir endlich entgegenhalten, dass es sich in den Fällen der zweiten Kategorie um Placenta praevia gehandelt habe. Bei der Anheftung der Placenta im unteren Uterussegment löst sich natürlich die Decidua vera von unten nach oben und hier hält der obere, noch nicht gelöste Theil der Decidua vera den Eisack in der Cervix zurïck. Solche Fälle waren aber ebenfalls nicht unter den von mir beobachteten. Dieselben sind ja leicht daraus zu diagnosticiren, dass bei ihnen sich die Nabelschnur an der Stelle inserirt, die man an dem in die Cervix polypenartig hineinragenden Blutcoagulum als unteren Eipol erkannt hat.

Durch diese Ausführungen glaube ich den Beweis von der Richtigkeit meiner Theorie über den Modus der, Ablösung der Decidua vera erbracht zu haben. Nur durch dieselbe erklärt sich auch die Häufigkeit der Retention der Decidua vera bei spontanem Verlaufe des Abortus. Dieselbe ist, wie schon obengesagt, meiner Meinung $n a c h$ bei natürlichem Verlauf des Abortus, sowie nach Anwendung der Tamponade nicht die A usnahme, sondern die Regel. Sagt doch auch Schrö$\left.\operatorname{der}^{1}\right)$ : „Die Decidua bleibt nicht selten längere Zeit zurück und giebt dann zu langwierigen Blutungen und unter Umständen durch Zersetzung zu infectiösen Erkrankungsformen Anlass."

Man erkennt die Retention, wenn man das Ei genau besichtigt und nur geringe Fetzen der Decidua an demselben findet, noch sicherer dadurch, dass man mit der Cürette in das Uteruscavum hineingeht. Ich habe, ebenso wie auch Fehling ${ }^{2}$ ), in

1) 1. c. S. 472 .

2) 1 . c. 
allen Fällen von spontan verlaufonem Abort, bei welchen ich selbst feststellte, dass der Eisack intact ausgestossen war - es sind ihrer mindestens ein Dutzend -, mittels der Cürette noch grosse Deciduafetzen herausbefördert, welche nach der mikroskopischen Untersuchung sich als aus den sämmtlichen Schichten der Decidua vera bestehend erwiesen. Da dies Fälle waren, in denen die Eiblase erhalten war, so wird der Einwand hinfällig, dass hier vor meinem Hinzukommen irgendwelche verunglückte Manipulationen zur Entfernung des Eies die physiologische Ausstossung desselben gestört hätten. Denn, zugegeben, dass in diesen Fällen Manipulationen zur Entfernung des Eies bereits vorgenommen waren, so sind dieselben doch als gänzlich gleichgültig zu betrachten, solange sie die Eiblase unverletzt liessen.

Ist die Eiblase gesprungen, so wird in den meisten Fällen die Ausstossung des Eies noch mehr erschwert. Wenn sich in diesen Fällen unter dem Einflusse der Tamponade oder bei ganz spontanem Verlaufe überhaupt etwas löst, so ist es die Placentaranlage. Die sich zuletzt lösende Decidua vera bleibt hier, wo der ganze Ablösungsprocess noch viel unvollkommener vor sich geht, als bei unversehrter Eiblase, fast regelmässig im Uterus zurück, unterhält andauernde Blutung und bildet einen günstigen Nährboden für etwa schon in das Uteruscavum eingedrungene Fäulnisskeime.

Der genannte Ablösungsmodus der einzelnen Eitheile ist meiner Meinung nach der regelmässige sowohl bei intactem, als auch bei geplatztem Eisacke, falls die Placenta nicht im unteren Uterinsegment inserirt. Jede andere Art der Ausstossung ist eine Abweichung von der Norm. So gebe ich $z u$, dass ausnahmsweise einmal die Decidua vera vor dem Eisacke resp. der Placenta ausgestossen wird. Dies geschieht aber nur, wenn die Decidua durch massige Blutextravasate zu einem festen, starren Gebilde umgewandelt ist, als welches sie dann der Verkürzung der Uteruswand nicht mehr zu folgen vermag. Auch wird man, wenn man einen Fall erst längere Zeit nach geplatztem Eisacke untersucht, hin und wieder einmal im Uterus nur noch die Placenta, nicht aber die Decidua vorfinden. Dieser Befund rührt aber dann daher, dass die Decidua mit dem Lochialflusse in kleinen Partikeln abgegangen ist, ähnlich wie die im Uterus nach normaler Geburt zurïckbleibende Decidua unmerklich mit dem Wochenflusse abgeht. 
Ich halte den von mir beobachteten Ablösungsmodus um so mehr für einen regelmässigen, weil die Fälle, die ich gesehen, vielfach durch Trauma, vielfach durch Abtreibungsversuche eingeleitet waren. Hier handelte es sich also, wie auch die mikroskopische Untersuchung mehrfach nachwies, um normale Decidua; von einer abnorm festen Verbindung derselben mit der Uteruswand, wie sie vielleicht durch entzündliche Veränderungen der Decidua erzeugt wird, konnte nicht die Rede sein.

Somit wird der Einwand hinfällig, dass der von mir beobachtete Ablösungsmodus und die häufige Retention der Decidua bei spontanem Verlaufe des Abortus eben nur bei Endometritis decidua vorkomme.

Die eben geschilderten Verhältnisse scheinen mir für eine rationelle Therapie von grosser Wichtigkeit. Halten wir fest, dass der eingeführte Finger sowohl bei unverletztem Ei als bei gesprungener Eiblase niemals zuerst die Decidua vera von der Uteruswand, sondern nur die Placentarstelle ablöst, so erhebt sich die Frage: Ist der Finger' im Stande, nach Ablösung des Eisackes und Expression desselben nunmehr auch die Decidua vera loszuschälen? Nach meinen Beobachtungen, die sich mit denen von Dohrn') und Prochownick ${ }^{2}$ ) decken, gelingt dies dem Finger nur sehr unvollkommen. Das Gefühl, welches die von Decidua vera noch bekleidete Uteruswand dem tastenden Finger darbietet, ist ganz dasselbe, wie es die von Decidua entblösste zeigt, und so ist man, selbst wenn man mit dem Finger einzelne Deciduatheile herausgebracht hat, doch noch im Unklaren, wo diese Stücke gesessen haben, welche Partien der Uteruswand man nun in Angriff zu nehmen hat und ob die betreffenden Deciduatheile in ihrer normalen. Trennungsschicht losgelöst sind. Eine reine Tantalusarbeit ist es endlich, wenn man Deciduastücke zum Theil losgelöst hat und es sich nun darum handelt, den noch vorhandenen Stiel abzutrennen. Die hin und her flottirenden Fetzen entweichen hartnäckig dem sie verfolgenden Finger, verschwinden vollständig, indem sie sich der Uteruswand wieder anlegen und machen eine Vorstellung darüber, an welcher Stelle sie noch anhaften, zur Unmöglichkeit. Dem könnte man nur einigermaassen dadurch abhelfen, dass man mit dem Finger-

1) 1. c.

2) Sammlung klinischer Vorträge, Nr. 57. 
nagel die ganze Decidua abkratzte. Allein erstens soll der Geburtshelfer keine langen Nägel besitzen, zweitens würde die Gefahr der Verletzung der Uterusmuskulatur vorhanden sein, und drittens wäre dieses Verfahren für den Geburtshelfer ein ungemein ermüdendes, für die Frau äusserst schmerzhaftes.

Zur Entfernung der Decidua vera ist also der Finger ganz ungeeignet, er ist hierfür nicht das beste Instrument, wie man es so oft behauptet findet. In der Entscheidung darüber, ob überhaupt der Uteruswand noch Decidua vera anhaftet, in der sicheren, schnellen, schmerzlosen, ungefährlichen Loslösung und Herausbeförderung der Decidua vera ist vielmehr der Cürette der Vorzug zu geben. Mittels der Cürette fühlt man sofort an dem eigenthümlichen knirschenden Geräusche, dass an der betreffenden Stelle keine Decidua vera mehr vorhanden ist. Das Cürettement ist in einer Minute abgemacht und nur wenig schmerzhaft, so dass Narkose bei demselben nicht nothwendig ist. Endlich ist das Cürettement bei sáchgemässer Führung der Cürette gänzlich ungefährlich. Die Gefahr des Cürettements könnte hierbei nur darin liegen, dass die Cürette vielleicht Verletzungen der Uterusmuskulatur selbst setzt. Dies ist nicht der Fall. Durch eine Reihe von mikroskopischen Untersuchungen, auf die ich unten näher eingehen werde, habe ich mich davon überzeugt, dass die Cürette die Decidua in derselben Schicht löst, in welcher bei spontanem Verlauf des Abortus sich die Trennung der Decidua vollzieht, nämlich in der tiefen ampullären Drüsenschicht!

Andererseits ist die Cürette wieder ganz ungeeignet zur Entfernung der noch adhärenten Placenta oder auch nur einzelner Theile derselben, der Placentarreste. Merkwürdigerweise wird aber die Cürette vielfach ganz unterschiedslos für die Entfernung von „Eiresten“ überhaupt empfohlen. 1) Mir ist es niemals gelungen, einen einigermaassen grösseren tastbaren Placentarrest, falls er nicht durch Zersetzung hochgradig erweicht war, mittels der Cürette in toto zu entfernen. Wenn man mit der Cürette grössere Excursionen macht, so fühlt man allerdings den Placentarrest sehr deutlich, ja derselbe fühlt sich mit der Cürette viel grösser an, als er in Wirklichkeit ist - man hat das Gefühl, als ob man über einen Berg

1) vgl. Bircher, Boeters, Mundé. 
herüberkommt und dann mit der Cürette in ein Thal hineinsinkt - ; allein, arbeitet man nun mit der Cürette auf dem Placentarreste herum, so bietet er dasselbe Knirschen, wie die von Decidua vera befreite Uteruswand, und man ist vollständig im Unklaren darüber, ob man noch am Placentarrest oder schon an der Uteruswand herumkratzt. Dies sind meiner Ansicht nach die Fälle, in welchen ein ungeübter Operateur noch am leichtesten mit der Cïrette den Uterus zu perforiren vermag. Von der Richtigkeit meiner Behauptung, dass einigermaassen grössere, nicht erweichte Placentarreste sich nicht vollständig mit der Cürette entfernen lassen, kann man sich leicht überzeugen, wenn man eine frische Placenta mit der Cürette bearbeitet. Die obersten uterinen Schichten entfernt dieselbe ganz leidlich, sobald sie aber auf einen grösseren Gefässstamm trifft, erzeugt sie dasselbe knirschende Geräusch, wie es die von den Eitheilen befreite Uteruswand hören lässt. Alsdann wird man natürlich mit dem Cürettement aufhören und Placentargewebe im Uterus zurücklassen.

Als Beispiel führe ich noch folgenden Fall an:

Journ.-Nr. 939. Unverehelichte Schröder, Ipara. Letzte Regel vor drei Monaten. Vor einigen Stunden Ausstossung einer dem dritten Monat entsprechenden frischen Frucht. Uterus gänseeigross, anteflectirt, Portio lang, spitz nach unten zulaufend, äusserer Muttermand geschlossen. Die eingeführte Cürette findet ein weites Uteruscavum, $;$ in welchem sie nach allen Richtungen ziemlich grosse Excursionen machen kann. Beim Versuch, die Uteruswand abzuschaben, sinkt die Cürette vielfach in scheinbar bedeutende Vertiefungen, und dann erscheint bald das bekannte Knirschen, so dass ich in der Meinung, alle Eireste entfernt zu haben, die Cürette herausziehe. Mit derselben kommen indessen nur einige kleine Placentarfetzen heraus. Auch die intrauterine Ausspiilung förderte nichts weiter zu Tage. Scheidentamponade. Nach zwölf Stunden Entfernung der Gazestreifen durch die Hebamme. Status idem. Muttermund geschlossen. Patientin steht, natürlich gegen unsere Vorschrift, auf und geht wieder ihrer gewöhnlichen Arbeit nach. Erst nach drei Tagen wird, ohne dass die Patientin inzwischen erbeblich geblutet, die Placenta piötzlich, nachdem die Patientin soeben ihr Bett aufgesucht, ausgestossen. Am folgenden Morgen stand Patientin abermals wieder. sofort auf und verrichtete ihre tägliche Beschäftigung. Zwei Monate später sah ich die Patientin wieder. Sie erfreut sich einer guten Gesundheit und hat speciell keinerlei Klagen über etwaige Unterleibsbeschwerden.

Von dem Augenblick an, wo sich die eigentliche Placenta gebildet hat, also im Allgemeinen von der Mitte des dritten Monats an, ist es also vergeblich, das gesammte $\mathrm{Ei}$ nur mittels der 
Cürette entfernen zu wollen. Für die Fälle von Abort im dritten Monate, die ja der Zahl nach die häufigsten sind, muss also die Therapie eine combinirte sein, nämlich: manuelle Entfernung des von der Decidua serotina und reflexa umschlossenen Eisackes oder nach geplatztem Sacke dieser Hüllen allein, Entfernung der Decidua vera durch Cürettement. Bei der manuellen Lösung handelt es sich ja stets, mag die Eiblase erhalten sein oder nicht, nur um die Ablösung der Placenta von der Uteruswand. Diese vollführt der Finger mit grosser Sicherheit und Leichtigkeit, selbst wenn der Eisack schon geplatzt ist.

In den ersten beiden Monaten der Schwangerschaft genügt die Cürette, wie schon oben angedeutet, vollständig zur totalen Entfernung des Eies. Da nun die Einführung des Fingers und das Manipuliren mit demselben im Uteruscavum viel schmerzhafter ist als das Cürettement und in manchen Fällen die Narkose erfordert, so empfehle ich, für die zwei ersten Monate der Sehwangerschaft den Uterus nur mit der Cürette auszuräumen.

Auch bei Aborten im dritten Monate giebt es seltene Fälle, in denen man behufs Ausräumung des Uterus nur mit der Cürette zu arbeiten gezwungen ist. Es sind dies Fälle, wo Zersetzung des Eies oder starke Blutungen die Entfernung des Eies erheischen, wo aber der innere Muttermund noch nicht für den Finger durchgängig ist. In diesen Fällen habe ich, was sich ohne längeres Manipuliren im Uterus löste, mit der Cürette herausgeholt, ausgespült und das Uteruscavum selbst mit Jodoformgaze austamponirt. Ich war hierdurch vor jeder Blutung gesichert, erzielte trotz der Tamponade einen prompten Abfall der Temperatur und erreichte die völlige Lösung der einzelnen Placentartheile, die sich regelmässig an den nach 12 Stunden entfernten Gazestreifen vorfanden. Durch diese Art des Vorgehens ersparte ich der Patientin und mir die Unbequemlichkeit einer langwierigen und nicht immer ungefährlichen Dilatation des Cervicalkanals.

Die combinirte Thérapie, also manuelle Lösung der Placenta, Lösung der Decidua vera resp. der Decidua vera sammt reflexa durch Cürettement, ist auch noch bei den Fehlgeburten des vierten und fünften Monats zu empfehlen, falls nach Ausstossung der Frucht die Expression der Placenta durch den $\mathrm{H} \ddot{o}-$ ning'schen Handgriff, wie so oft, nicht gelingt. Hier ist jeden- 
falls ein exspectatives Verhalten oder die Scheidentamponade ganz $\mathrm{zu}$ verwerfen, falls man nicht Zeit hat, bis in Infinitum bei der Patientin sitzen zu bleiben. Verlässt man aber die Patientin, so kann jeden Augenblick eine recht bedenkliche Blutung eintreten, die sich bei der Scheidentamponade in solchen Fällen nur in eine innere verwandelt.

Geht man nun behufs manueller Lösung der Placenta mit zwei Fingern in die Scheide ein — nur, wenn der Uterus sehr hoch, etwa in Nabelhöhe steht, ist es in einzelnen Fällen nothwendig, die ganze Hand in die Scheide einzuführen, um mit einem oder zwei Fingern das ganze Uteruscavum abtasten zu können -, so. findet man häufig schon einen Zipfel der partiell gelösten Placenta aus dem Muttermunde herausragen. Ich habe, um nicht in den Uterus eingehen zu müssen, es mehrfach versucht, den Zipfel mit einer Kornzange zu fassen und die Placenta herauszudrehen. Allein, seitdem ich gefunden, dass hierbei in der Regel Placentarreste zurückblieben, die dann viel schwerer zu entfernen waren, bin ich von diesem Verfahren ganz zurïckgekommen und löse mit einem oder zwei Fingern die Placenta direct an dem Orte ihrer Adhärenz. Ich brauche wohl kaum bei dieser Manipulation darauf aufmerksam zu machen, wie wichtig für eine rasche und vollständige Ablösung der Placenta die äussere Hand ist. Dieselbe muss theils den Uterus fixiren, theils die betreffende Partie, wo der innere Finger noch die Placenta abzuschälen hat, demselben entgegendrängen.

Man könnte mir die Behauptung entgegenstellen, dass bei Fehlgeburten des vierten und fünften Monats die manuelle Lösung der Placenta genügt, dagegen aber die Exfoliirung der nunmehr schon sehr atrophischen Decidua ohne Gefahr einer erheblichen Blutung ruhig der Natur überlassen werden kann. Indessen habe ich in mehreren dieser Fälle noch eine Decidua von 3 bis $6 \mathrm{~mm}$ Dicke aus dem Uterus durch Cürettement entfernt. Dass bei schon eingetretener Zersetzung der Eihäute die Retention einer so dicken Decidua die Fäulniss begünstigt, ist unzweifelhaft, und dass sie starke Blutungen unterhalten kann, davon habe ich mich in mehreren Fällen überzeugt. Hier waren oft Tage lang vorher Frucht und Placenta ausgestossen worden, und es hatte die Blutung in oft sehr starkem Grade bis zu dem Augenblick angedauert, wo ich die Decidua mittels Cürettement entfernte. Besonders auffallend war in dieser Beziehung ein Fall von Fehlgeburt 
des vierten Monats, bei welcher sich nach vollständiger manueller Entfernung der Placenta der Uterus absolut nicht contrahirte und eine profuse Blutung eintrat. Dieselbe stand sofort, nachdem das Cürettement die $6 \mathrm{~mm}$ dicke, mit der Reflexa noch nicht verwachsene Decidua vera herausbefördert hatte.

In anderen Fällen allerdings, bei Mehrgebärenden mit schlaffem Uterus, bleibt die Atonie des Uterus auch nach Entfernung der Decidua bestehen. Hier injicirte ich Ergotin, machte heisse uterine Ausspülungen, ging aber dann bei Erfolglosigkeit dieser Mittel rasch zur Uterustamponade ${ }^{1}$ ) mit langen Jodoformgazestreifen über. Selbst bei septischer Fehlgeburt erlebte ich hier jedesmal einen raschen Abfall der Temperatur. Als Beispiel führe ich folgenden Fall an:

Journ.-Nr. 885. Frau Bamberg, 43 Jahre, XXIV para, 19 normale Geburten, 4 Aborte voransgegangen. Fehlgeburt VI. M., Frucht bereits ausgestossen. Temperatur 40,3. Stinkender Ausfluss. Manuelle Lösung der zersetzten Placenta, Cürettement. Wegen Andauer der Blutung nach fruchtloser Anwendung der gewöhnlichen Mittel Tamponade des Uterus. Zwölf Stunden später Entfernung der Gazestreifen. Temperatur normal. Weiterer Verlauf gut.

Nur muss man bei diesen Fällen mit der Anwendung von Carbolsäurelösungen vorsichtig sein: ich habe hierbei mehrere Male den „Carbolzufall" in ausgeprägtester Form zu Gesicht bekommen. Mit einem Schlage sistirten Puls und Athmung, und es bedurfte längerer künstlicher Athmung und Aetherinjectionen, um die Patientin wieder ins Leben zurückzurufen. Noch Tage lang nachher zeugte der charakteristische Carbolurin von der schnellen Resorption der 3 proc. Lösung. Seitdem wende ich in solchen Fällen eine 0,3 proc. Salicylsäurelösung an.

1) Nach den guten Erfolgen, welche ich bei Fehlgeburten durch die Uterustamponade erzielte, habe ich dieselbe in dieser Weise auch bei Atonie des Uterus nach normaler Geburt angewandt. Man fasst die vordere Lippe mit Kugelzangen und führt die Streifen mit einer langen anatomischen Pincette ein, deren Lage im Uterus man durch die äussere Hand controlirt. Das Resultat, sowohl in Betreff der prompten Blutstillung, als auch des weiteren Befindens, ist ein so gutes, dass ich den Liquor ferri ganz aus meiner Tasche verbannt habe. 


\section{Specieller Theil.}

Von Anfang September 1886 bis Ende Mai 1887 wurden in der geburtshïlflichen Poliklinik der Charité 250 Fälle von Abort behandelt. Unter diesen endeten 2 mit dem Tode. 122 dieser Fälle sind von mir persönlich beobachtet und behandelt und liegen meiner Arbeit zu Grunde. Die Vertheilung derselben auf die einzelnen Monate, sowie die Therapie veranschaulichen die beifolgenden zwei Tabellen, von denen die erste die Fälle von nachweislich unverletztem Eisacke umfasst.

Tabelle I. Eisack unverletzt.

\begin{tabular}{|c|c|c|c|c|c|c|c|}
\hline $\begin{array}{c}1 \\
\text { Zeit } \\
\text { des } \\
\text { Abortus }\end{array}$ & $\begin{array}{c}2 \\
\text { Zahl } \\
\text { der } \\
\text { Eier }\end{array}$ & $\begin{array}{c}3 \\
\text { Manuelle } \\
\text { Lösung } \\
\text { und } \\
\text { Cürette- } \\
\text { ment }\end{array}$ & $\begin{array}{c}\text { 4 } \\
\text { Manuelle } \\
\text { Lösung } \\
\text { des Eies } \\
\text { in toto }\end{array}$ & $\begin{array}{l}5 \\
\text { Expres- } \\
\text { sion und } \\
\text { Cürette- } \\
\text { ment }\end{array}$ & $\begin{array}{l}6 \\
\text { Expres- } \\
\text { sion des } \\
\text { Eies } \\
\text { in toto }\end{array}$ & $\begin{array}{c}7 \\
\text { Cürette- } \\
\text { ment (Ei- } \\
\text { sack in d. } \\
\text { Scheide } \\
\text { geboren) }\end{array}$ & $\begin{array}{l}8 \\
\text { Sprengung der } \\
\text { Blase, Extrac- } \\
\text { tion des Foetus, } \\
\text { manuelle Lösung } \\
\text { der Placenta }\end{array}$ \\
\hline $\begin{array}{l}\text { 2. Monat } \\
\text { 3. " } \\
\text { 4. " } \\
5 . \quad " \\
6 . \quad "\end{array}$ & $\frac{2}{27}$ & $\begin{array}{r}1 \\
14 \\
- \\
-\end{array}$ & $\begin{array}{l}\overline{2} \\
- \\
-\end{array}$ & $\begin{array}{l}- \\
- \\
-\end{array}$ & $\begin{array}{l}1 \\
1 \\
- \\
-\end{array}$ & $\begin{array}{l}- \\
- \\
-\end{array}$ & $\begin{array}{c}- \\
- \\
1 \\
1\end{array}$ \\
\hline Sa. & 31 & 15 & 2 & 4 & 2 & 6 & 2 \\
\hline
\end{tabular}

Tabelle II. Entfernung von Eiresten.

\begin{tabular}{|c|c|c|c|c|c|}
\hline $\begin{array}{c}1 \\
\text { Zeit } \\
\text { des } \\
\text { Abortus }\end{array}$ & $\begin{array}{c}2 \\
\text { Zahl } \\
\text { der } \\
\text { Eier }\end{array}$ & \begin{tabular}{|c|}
3 \\
Manuelle \\
Lösung der \\
Placenta und \\
Cürettement
\end{tabular} & $\begin{array}{c}4 \\
\text { Manuelle } \\
\text { Lösung der } \\
\text { Placenta }\end{array}$ & \begin{tabular}{|c|}
$\mathbf{5}$ \\
Expression \\
der Placenta \\
und Cürette- \\
ment
\end{tabular} & $\begin{array}{c}6 \\
\text { Cürette- } \\
\text { ment }\end{array}$ \\
\hline $\begin{array}{l}\text { 2. Monat } \\
\text { 3. } \quad ", \\
4 . \quad " \\
5 . \quad " \\
6 . \quad "\end{array}$ & $\begin{array}{r}9 \\
44 \\
32 \\
5 \\
1\end{array}$ & $\begin{array}{r}2 \\
20 \\
23 \\
3 \\
1\end{array}$ & 1 (Placentarpolyp) & $\begin{array}{l}- \\
1 \\
1 \\
-\end{array}$ & $\begin{array}{r}7 \\
23 \\
7 \\
1 \\
-\end{array}$ \\
\hline Sa. & 91 & 49 & 2 & 2 & 38 \\
\hline
\end{tabular}

Von den 31 Abortfällen mit unverletztem Eisacke (Tab. I.) wurde in 15 Fällen der noch im Fundus adhärente Eisack manuell, die Decidua vera durch die Cürette gelöst. Was nun die Frage anlangt, ob nicht hier ein exspectatives Verhalten das eine oder andere kindliche Leben gerettet hätte, so ist darauf zu be- 
merken, dass in 12 Fällen der Fötus macerirt, bezw. überhaupt nicht mehr vorhanden war. Von den 3 übrigen Fällen handelte es sich in dem einen um hochgradigste Sepsis der Mutter (Fall 576) - eine Stunde nach beendeter Ausräumung trat hier der Tod ein --, in dem zweiten um eine Retroflexio uteri gravidi mit Incarcerationserscheinungen; in dem dritten machte allerdings die am Ende des dritten Monates befindliche Frucht sogar mehrere Secunden lang Bewegungen, allein es war eine starke Blutung vorausgegangen, der verkürzte Cervicalkanal bequem für einen Finger durchgängig und die manuelle Lösung der Placenta ungemein leicht; es war also der Zusammenhang zwischen Eisack und Uteruswand bereits bedeutend gelockert. Somit ist die Behauptung wohl nicht zu gewagt, dass in keinem dieser Fälle der Abort bei exspectativer Behandlung aufgehalten worden wäre. Noch weniger wäre dies bei den 12 Fällen der Columnen 4 bis 7 (der Tab. I) der Fall gewesen. Hier befand sich der Eisack theils in der Cervix, theils schon in der Scheide.

In 4 dieser Fälle, in welchen das Ei $2 \mathrm{Mal}$ manuell, $2 \mathrm{Mal}$ durch den Höning'schen Handgriff allein in toto entfernt wurde, lag dasselbe in der Cervix. Diese theilweise Austreibung hatte aber die Natur nur vermittelst einer starken Blutung erreicht. Der Puls war bei den betreffenden Frauen fadenförmig, die Gesichtsfarbe blass, in dem einen Falle war ausser einer vorausgegangenen starken äusseren Blutung die Scheide ballonartig durch Blutgerinnsel ausgedehnt. Hier dachte ich sogar an die Transfusion, erreichte aber ejne Besserung des Pulses durch eine Eingiessung in den Mastdarm und die üblichen Excitantien. In 3 dieser Fälle ging ich noch mit der Cürette in das Uteruscavum ein, förderte aber nur ganz minimale Gewebstrümmer zu Tage. Die Hebammen hatten in 3 Fällen tamponirt, doch hatte es hinter den Tampons ruhig fortgeblutet.

Von den 4 Fällen von Expression und Cürettement (Columne 5 der Tab. I) ist in einem Falle eine sehr starke vorausgegangene Blutung notirt; in einem zweiten war die Scheide von geronnenem Blute ausgefüllt, ohne dass indess bei der sehr kräftigen jungen Person die Wirkung auf den Puls sehr hervorgetreten wäre.

Ich führe diese Fälle besonders an, um za zeigen, wie gefährlich sich ein Abort gestalten kann, der völlig der Natur überlassen oder nur mit Tamponade behandelt wird. Und trotz der colossalen Blutung hatte die Natur die spontane Ausstossung des Eies doch nicht zu Wege gebracht! 
In den 6 Fällen der Columne 7 war die durch die Natur bewirkte Ausstossung des Eies ebenfalls eine unvollkommene. Der Eisack war allerdings spontan in die Scheide ausgestossen, die Decidua vera jedoch abgerissen und im Uteruscavum zurückgeblieben. In $\check{5}$ Fällen musste hier wegen Fortdauer der Blutung das Cürettement noch längere Zeit nach der Entfernung des Eisackes vorgenommen werden. In dem 6 . Falle wurde wegen Fiebers der Patientin das Cürettement sofort an die Wegnahme des Eies angeschlossen.

Auch unter den 23 Fällen von Abort im dritten Monat, in welchen wegen Retention der Decidua vera nur das Cürettement erforderlich war (Tab. II, Columne 6), befinden sich mehrere, in welchen mir ein bereits spontan ausgestossener unverletzter Eisack gezeigt wurde. Es waren ihrer - dessen erinnere ich mich mit Bestimmtheit - mindestens ein halbes Dutzend. Die Zahl der Fälle, in welchen der Eisack spontan ausgestossen, die Decidua vera jedoch zurückgeblieben war, beträgt somit 12. Auf Grund derselben halte ich den schon oben ausgesprochenen Satz für berechtigt, dass bei spontanem Verlauf des Abortus oder bei Tamponade die Retention der Decidua vera nicht die Ausnahme, sondern die Regel ist.

Durch eine grössere Statistik werden diejenigen, welche den Abort mehr exspectativ behandeln, diese Behauptung sicher bekräftigen können. Dieselbe wird noch durch die Thatsache gestützt, dass es von 6 Fällen von Expression des Eies, welche doch die natïrliche Ausstossung völlig nachahmt, 4 Mal zur Retention der Decidua vera kam.

Manches Interessante bieten die 2 letzten Fälle der Columne 8. Der eine erheischte die rasche Entleerung des Uterus wegen septischer Zersetzung seines Inhaltes.' Dieselbe charakterisirte sich durch stinkenden Ausfluss ex utero, $40^{\circ}$ Temperatur und einen scharlachähnlichen Ausschlag. Es machte ziemliche Schwierigkeit, die macorirte, dem fünften Monat angehörende Frucht stückweise durch den nur für einen Finger durchgängigen Cervicalkanal zu extrahiren. Am folgenden Tage war Patientin fieberfrei und ihr Befinden auch weiterhin ein gutes. Von J. Veit ${ }^{1}$ ) sind zwei analoge Fälle beschrieben worden.

Bei dem zweiten Falle, einer Fehlgeburt des sechsten Monats,

1) Zeitschrift für Geburtshülfe, Bd. IV. 
war die $5 \mathrm{~mm}$ dicke, sehr gefässreiche Decidua in toto ausgestossen. Alsdann hatte sich die Blase, nur von Chorion und Amnion gebildet, vollständig aus der Scheide herausgedrängt und setzte sich nur mittels eines dünnen Stieles durch den für einen Finger durchgängigen rigiden Cervicalkanal in das Uteruscavum fort. In letzterem befand sich nur die Frucht, die gesammte Fruchtwassermenge war in den vor der Vulva liegenden Abschnitt der Eiblase geströmt. Was die Aetiologie dieser primären isolirten Ausstossung der Decidua anlangt, so soll dieselbe nach Küstner, der, wenn ich nicht irre, zwei derartige Fälle beschrieben hat, auf Syphilis beruhen. In der That hatte auch meine Patientin nur Aborte und Fehlgeburten durchgemacht. Objectiv war an ihr allerdings nichts von Syphilis nachzuweisen, auch die Anamnese ergab ein negatives Resultat.

In sämmtlichen 91 Fällen der Tabelle II handelte es sich um das Zurückbleiben von „Eiresten'. Nach meiner Ansicht ist dieser Ausdruck ein viel zu allgemeiner, da es für die Therapie doch einen wesentlichen Unterschied macht, ob nur die Decidua vera zurückgeblieben ist, oder ob sich im Uterus ausserdem noch der ganze, wenn auch geplatzte Eisack befindet. Im ersteren Falle ist das Cürettement die beste Therapie, im zweiten muss man den geplatzten Eisack, ebenso wie den unverletzten, an der Placentarstelle mit dem Finger von der Uteruswand losschälen und alsdann die Decidua vera durch Cürettement entfernen. Betrachtet man dann den losgeschälten Eirest genauer, so wird man sehr häufig finden, dass er dem unverletzten Eisacke ziemlich nahe steht. Die mit hämorrhagischen Herden durchsetzten verdickten Eihäute, die Decidua reflexa und das Chorion fallen nach Abfluss des Fruchtwassers nicht zusammen, sondern umschliessen eine vielleicht um die Hälfte verkleinerte Eihöhle. Der ganze Eisack ist dabei durch den Uterusdruck verschmälert, in die Länge gezogen, kurz in ein strangartiges Gebilde umgewandelt, welches bei oberflächlicher Betrachtung eben nur als ein Placenta- oder Deciduarest imponirt. Sucht man diesen geplatzten Eisack durch das Cürettement allein $\mathrm{zu}$ entfernen, so wird mian in den herausgeschabten Massen sehr häufig durch das Mikroskop Chorionzotten nachweisen; beschränkt man aber, wie es mit seltenen Ausnahmen das Richtige ist, das Cürettement auf die Entfernung der Decidua vera, so wird man in dritten Monate, in welchem Decidua vera und reflexa noch nicht mit einander verwachsen sind, niemals in den ausgeschabten Massen Chorionzotten finden. 
Die Decidua vera habe ich in allen Fällen gefunden, in denen ich vorher den geborstenen Eisack an der Placentarstelle manuell gelöst hatte. Dies wäre nicht möglich gewesen, wenn sich die Decidua vera von allen Eibestandtheilen zuerst löste. Denn dann hätte sie entweder schon ausgestossen worden sein oder mit dem geplatzten Eisacke zu gleicher Zeit manuell entfernt werden müssen. Es gelten eben für das geborstene $\mathrm{Ei}$ in Betreff der Lösung der Decidua vera dieselben Verhältnisse, wie bei unverletztem Ei: die Decidua vera löst sich auch hier von allen Eibestandtheilen zuletzt. Deswegen musste ich sogar noch in 7 Fällen des vierten Monates und in 2 aus dem fünften und sechsten, in denen die Placenta vollständig ausgestossen war, die Blutung aber andauerte, das Cürettement machen. Ich konnte in den herausgeholten Massen nichts von Amnion finden und schliesse daher aus diesem negativen Befunde, dass in manchen Fällen die Verklebung zwischen Decidua vera und reflexa im vierten Monate noch nicht vorhanden ist. In einem Falle aus dem vierten Monat, welchen ich darauf hin genau untersuchte, sass in der That ein grosser Lappen der Reflexa mit dem Chorion und Amnion an der Placenta. Dass es sich wirklich um diese Eihäute handelte, bestätigte die mikroskopische Untersuchung. Ich nahm dieselbe auch an den mittels der Cürette herausgeholten $4 \mathrm{~mm}$ dicken Massen vor und fand, dass dieselben nur aus Decidua vera bestanden. Dieselbe zerfiel in eine Zell- und Drüsenschicht, von Chorionzotten oder Amnion war nichts vorhanden.

Es ist ja bei einiger Uebung sehr leicht, schon makroskopisch Placentarstücke, Decidua reflexa und Decidua vera von einander zu unterscheiden. Erstere zeichnen sich durch ein mehr festes, derbes Gefüge und dunklere Färbung aus; die Decidua vera besitzt im Vergleich zur Decidua reflexa einen viel grösseren Gefässreichthum, sie ist drei bis vier Mal so dick und zeigt in so charakteristischer Weise eine glatte, nur von den Mündungen der Uterusdrüsen durchlöcherte und eine rauhe, fetzige, mit Blutcoagula besetzte Oberfläche, die der mit dem Chorion in Verbindung gebliebenen Decidua reflexa völlig abgeht.

Allein die aus der makroskopischen Betrachtung gewonnene Ueberzeugung, dass ich in allen meinen Fällen wirklich die Decidua in allen ihren Schichten aus dem Uterus ausgeschabt, genügte mir nicht. Man hätte mir immer noch vorwerfen können, dass ich vielleicht nur die tiefsten Schichten der Decidua, die 
physiologischer Weise im Uterus verbleiben, oder gar einfach gewucherte Uterusschleimhaut entfernt hätte. Um dem vorzubeugen, habe ich eine Reihe von mikroskopischen Untersuchungen vorgenommen, welche theils die herausgeschabte, theils die spontan ausgestossene Decidua vera, theils die Decidua reflexa unverletzter Eier betrafen. Als ich an diese Untersuchungen heranging, legte ich mir zunächst die Fragen vor:

In welcher Schicht löst sich bei Abort physiologischer Weise die Decidua vera?

Und ferner:

Sind wir durchirgendwelche therapeutischen Eingriffe, speciell durch das Cürettement, im Stande, die Ablösung der Decidua vera von der Uteruswand in derselben Schicht zu bewerkstelligen, wie es bei der spontanen Ausstossung geschieht?

In meinen sämmtlichen Fällen, die ich darauf hin mikroskopisch untersucht habe, fand, um das Resultat gleich vorweg zu nehmen, die spontane Lösung der Decidua vera stets in der Drüsenschicht, und zwar in der tiefen alveolären Schicht statt. In derselben Schicht löste stets die Cürette die Decidua vera ab. Deciduapräparate von Fällen, in denen die Decidua vera nur zum Theil spontan ausgestossen, zum Theil mit der Cürette entfernt war, gaben ein vollständig gleiches Bild. Das Cürettement ahmt also die natürliche Loslösung der Decidua vera von der Uteruswand in vollkommener Weise nach, es setzt keine tiefgreifende Verletzung der Uteruswand. Dies geht auch aus der zuerst von Düvelius'), weiterhin auch von Heinricius ${ }^{2}$ ) festgestellten Thatsache hervor, dass Frauen, die cürettirt worden sind, späterhin eine normale Schwangerschaft durchmachen. Ich habe ebenfalls in unserer Poliklinik öfter Gelegenheit gehabt, die Entbindungen von Frauen zu leiten, die früher von uns wegen eines Abortus cürettirt waren.

Die Literatur über die spontane Ablösung der Decidua vera bei Aborten ist nicht sehr umfangreich. Die Angabon beziehen sich fast alle auf die Lösung der Decidua nach normaler Geburt. Hier lösen sich nach Langhans ${ }^{3}$ ) die Eihäute an der

1) Zeitschrift für Geburtshülfe, Bd. X.

2) l. c.

3) Dieses Archiv, Bd. VIII, S. 287. 
Grenze zwischen Zell- und ampullärer Schicht in der Weise, dass die ampulläre Schicht fast ganz zurückbleibt. Bei den $\mathrm{Ab}$ orten walten, wie Langhans sich kurz ausdrückt, dieselben Bedingungen ob: „Für diejenigen, welche auch nur wenige Abortuseier untersucht haben, bedarf es nur des Hinweises auf das bekannte maschige Aussehen der Vera an ibrer Trennungsschicht, und wenn ich nicht irre, ist auch schon öfters die Ansicht geäussert worden, dass dasselbe auf der Erweiterung der Drüsen beruhe."

Auch Leopold 1) deutet darauf hin, dass sich bei Aborten die Decidua vera in der ampullären Schicht löst, indem er sagt: „Die Hauptaufgabe der Uterindrüsen für den schwangeren Uterus liegt in der Bildung der über die gesammte Körperhöhle ausgebreiteten spongiösen Schicht, in welcher, wie Langhans beschrieben, die Lösung der mütterlichen Eihäute vor sich geht."

Gottschalk ${ }^{2}$ ) endlich bezieht die in seinem Präparate eines frischen schwangeren Uterus der fünften Woche deutlich hervortretende Trennung der Decidua vera von der Uteruswand - eine Trennung, die sich durch das lockere Gefüge der tiefen alveolären Schicht kennzeichnet - nur auf die Losstossung der Decidua am normalen Ende der Schwangerschaft.

Thatsächlich unterscheidet sich übrigens die Anschauung von Langhans nicht wesentlich von der Friedländer's, welcher bei normaler Geburt die Abtrennung der Decidua in die Zellschicht verlegt. Prüft man nämlich die Langhans'sche Abbildung ${ }^{3}$ ) auf seine oben citirten Angaben von der Lösung der Decidua, so geht daraus hervor, dass nach seiner Anschauung $4 / 6$, nach derjenigen Friedländer's $5 / 6$ der Vera im Uterus zurïckbleiben.

Um mich selbst genau über diesen Punkt zu unterrichten, habe ich in 11 Fällen die von mir mittels der Cürette herausgeholten Massen mikroskopisch untersucht. In 2 dieser Fälle stand mir auch die (zum Theil) spontan ausgestossene Decidua

1) Dieses Archiv, Bd. XI, S. 455.

2) Ibid., Bd. XXIX.

3) Dieselbe ist in dem Lehrbuch von $Z_{w}$ eifel (S. 48) wiedergegeben. Die die blinden Drüsenendigungen enthaltende Schicht ist übrigens, wenn man die Abbildungen ron Leopold (l. c.) zur Vergleichung heranzieht, viel zu breit gezeichnet. Nach Leopold, ,senken sich die tiefsten Spitzen der Drüsen nur ein wenig in die intermuskulären Buchten ein." 
vera zu Gebote. In 2 weiteren von mir untersuchten Fällen war die ganze Decidua vera zusammen mit dem unverletzten Eisacke durch leichten Druck auf letzteren entfernt worden.

Ich beabsichtige nicht, den mikroskopischen Befund der 13 Fälle genau zu beschreiben, ich würde dann $13 \mathrm{Mal}$ ungefähr dasselbe sagen müssen. Ich beschränke mich daher auf die Beschreibung der 2 Fälle, in welchen die Decidua vera theils herausgeschabt ist, theils spontan abging, und auf den einen der 2 Fälle, in welchem das ganze $\mathrm{Ei}$ auf leichten Druck mit der Decidua vera entfernt wurde.

Journ. - Nr. 102. Frau Birghan, sechs normale Geburten, vor der letzten zwei spontan verlaufene Aborte. Letzte Regel vor nicht ganz drei Monaten. Seit sechs Stunden Blutung. Ausstossung der Frucht und der Placenta vor drei Stunden. Danach wegen andauernder Blutung Tamponade seitens der Hebamme.

Temperatur 37,2, Puls klein. Hinter den Tampons liegt ein grosses Deciduastück, doch sind im Uterus noch fetzige Massen zu fühlen. Das Cürettement fördert noch mehrere bis bohnengrosse Stücke heraus, die stark mit Blut durchsetzt sind und makroskopisch die Decidua in allen ihren Schichten darstellen. Die Stücke sind nämlich 3 bis $4 \mathrm{~mm}$ dick, haben eine glatte Oberfläche, die stellenweise feine Oeffnungen erkennen lässt, und eine rauhe, der glatten gegenüberliegende Seite, welche im Wasser zahlreiche flottirende Fäden zeigt.

A. Die mikroskopische Untersuchung dieser herausgeschabten Massen ergiebt Folgendes:

Der Schnitt lässt zwei Schichten erkennen, eine Zell- und eine Drüsenschicht. Die Drüsenschicht misst in der Dicke 2,7 mm, die Zellschicht nur 0,3 mm. Die oberste Lage der Zellschicht wird durch eine mehrfache Schicht langgestreckter, der Oberfläche paralleler Zellen gebildet, welche bei schwacher Vergrösserung durch ihre stärkere Färbung einen Epithelsaum vortäuschen. Es folgen dann in der Zellschicht und der zunächst angrenzenden Drüsenschicht grosse, theils runde, theils sternförmige Zellen mit grossem glänzendem Kerne. In der tieferen Partie der Drüsenschicht sind die Zellen sehr lang, aber schmal, spindelförmig und in dichten Zügen angeordnet. Sie umgeben die Gefässe concentrisch, zwiebelschalenförmig, wie Wald e yer es treffend ausdrückt. Zwischen diesen grossen Zellen liegen zahlreiche gekernte Rundzellen von der Grösse weisser Blutkörperchen.

Die Drüsenräume der Drüsenschicht sind sämmtlich stark in 
die Breite ausgezogen und parallel oder schräg zur Oberfläche angeordnet. Sie zeigen Ausbuchtungen, die ihnen stellenweise ein sägeförmiges oder korkzieherartiges Aussehen verleihen. Ein Epithelsaum lässt sich nur an einzelnen Drüsen der tiefsten alveolären Schicht nachweisen. Das Epithel derselben ist niedrig cubisch und lässt nicht in allen Zellen den Kern deutlich erkennen. Die Drüsenräume liegen bis zu sieben Etagen übereinander, die sie trennenden Septa sind nur schmal. An einer Stelle des Präparates sieht man eine der oberflächlichen Drüsenschicht angehörige Drüse, derèn unteres Ende stark ausgebuchtet ist, mit einem schmalen Gange die Zellschicht durchsetzen und die freie Oberfläche erreichen.

Die Gefässe sind zahlreich, in der Tiefe stark gewunden. Die Zellschicht ist stellenweise in ihrer ganzen Dicke von Blutextravasaten durchsetzt, die dicht aneinander liegen. In den angrenzenden Partien der Drüsenschicht sind sie viel kleiner und mehr zerstreut, in der tiefen Drüsenschicht fehlen sie ganz.

B. Die mikroskopische Untersuchung der spontan ausgestossenen Deciduahälfte hat fast das gleiche Ergebniss. Die Dicke der Zell- und Drüsenschicht ist dieselbe, die Drüsenräume sind ebenfalls bis zu sieben Etagen übereinander geschichtet. Der einzige Unterschied besteht darin, dass bei diesem Präparate die Blutextravasate fast gänzlich fehlen. Es liegen nur vereinzelte, kleine in der Zellschicht.

Journ.-Nr. 115. Frau Röhl, 25 Jahre alt. Fine normale Geburt vorausgegangen. Letzte Regel vor nicht ganz drei Monaten. Hebanme hat vor mehreren Stunden wegen plötzlich aufgetretener profuser Blutung tamponirt.

Temperatur 37,3, Puls klein. Gesichtsfarbe blass. Hinter den Tampons liegt ein faustgrosses Blatgerinnsel. Uterus ist retrovertirt, etwa $9 \mathrm{~cm}$ lang, Portio verkürzt, der Muttermund lässt den Finger eindringen; $1 / 2 \mathrm{~cm}$ über demselben fühlt man die Spitze des Eies. Der Finger dringt, ohne den leisesten Widerstand zu finden, bis zum Fundus vor und löst hier sehr leicht den besonders nach hinten zu adbärenten Eisack. Expression desselben. Der wieder eingeführte Finger fühlt oberhalb der Mitte zwischen Muttermund und F'undus flottirende Fetzen, die derselbe nur zum Theil entfernen kann. Oberhalb und unterhalb fühlt sich die Uterusschleimhaut gleichmässig glatt an. Das Cürettement fördert mehrere grosse Deciduafetzen heraus. Eine nochmalige Digitalexploration ergiebt eine allseitig glatte Uterusinnenfäche. Uterusausspïlung. Keine Spur von Blutung mehr. Weiteres Befinden gut. 
Das Ei ist etwa hühnereigross und bis auf das untere Drittel noch mit $1 \mathrm{~cm}$ langen Chorionzotten versehen, die nach dem oberen Eipole hin an Mächtigkeit zunehmen. Die Reflexa ist grösstentheils vom Chorion abgelöst und hängt mit demselben nur noch durch eine schmale Brücke zusammen. Mit der Reflexa verbunden ist ein ungefähr $2 \mathrm{~cm}$ breiter Streif der Vera, die besonders gegen die Reflexa hin eine auffällig gallertige Beschaffenheit hat und hier nur dünn ist. Der Fötus ist $1 \mathrm{~cm}$ lang, macerirt.

A. Mikroskopischer Befund der herausgeschabten Decidua:

Schnitt $4 \mathrm{~mm}$ breit. Zellschicht fehlt stellenweise; wo sie erhalten, ist sie șehr dünn, bis $0,2 \mathrm{~mm}$. In der Drüsenschicht liegen die Drüsen in fünf bis sieben Lagen übereinander. Die Mehrzahl derselben ist klein, hat eine sternförmige Figur und besitzt ein völlig zusammenhängendes, ziemlich hohes Epithel. Die grossen Deciduazellen sind ziemlich spärlich vorhanden, in den Septa liegen kleinere Spindelzellen. Gefässe wenig zahlreich, keine Blutextravasate.

B. Befund der mit dem Eisacke abgelösten Decidua (von der dünsten Partie genommen):

Schnitt $2 \mathrm{~mm}$ dick, Zellschicht 0,5 mm. Drüsenschicht 1,5 mm dick. Die Drüsen liegen bis zu vier Schichten übereinander, sind theils mehr rundlich, theils in die Breite gezogen. Epithelsaum nicht zu entdecken. Doch liegen in den Drüsen Zellen und Zelltrümmer, die als losgelöste Epithelien zu deuten sind. Zahlreiche grosse Deciduazellen.

Betrachten wir noch kurz die klinische Seite dieses Falles, welcher in schlagender Weise meine Behauptungen in Betreff des Ablösungsmodus der Vera bestätigt. Die Frau hatte stark geblutet und trotz der Tamponade noch Blut verloren. Der Muttermund liess den Finger bequem eindringen, und derselbe gelangte, ohne irgendwo einen Widerstand zu finden, bis zum Fundus. Nur hier war das Ei adhärent. Nach Ablösung des Eies an dieser Stelle hätte man gemäss den Ausführungen Schröder's ${ }^{1}$ ) erwarten sollen, dass das ganze $\mathrm{Ei}$ mit der Vera durch den $\mathrm{Hö-}$ ning'schen Handgriff nach aussen befördert wurde. Das wäre auch der Fall gewesen, wenn sich die Decidua vera von unten

1) Lehrbuch der Geburtshülfe. 8. Aufl. S. 481. 
nach oben löste. Thatsächlich hatte sich aber hier nur der obere Theil der Decidua in einer Länge ron $2 \mathrm{~cm}$ gelöst. Der untere grössere Theil sass noch fest, seine obere Grenze wurde durch die flottirenden Fetzen bezeichnet. Wie schon oben bemerkt, unterschied sich für den tastenden Finger die obere nicht von Decidua - bekleidete Partie der Uteruswand in keiner Weise von der unteren. Wir haben uns also vorzustellen, dass zur Zeit des therapeutischen Eingriffes der Zusammenhang zwischen Placentaranlage und Uteruswand einerseits und zwischen oberem Theile der Vera und Uteruswand andererseits bereits gelockert war. Deswegen liess sich der Eisack so leicht abschälen, und der schon gelockerte Theil der Vera löste sich von der Uteruswand durch die Schwere des nach unten sinkenden Eisackes. Der noçh nicht gelockerte untere Theil der Vera dagegen adhärirte der Uteruswand noch zu fest, um durch die Schwere des Eisackes abgelöst zu werden. Vielmehr bewirkte dieselbe eine Abtrennung der oberen Partie der Vera von der unteren. Die Lockerung des oberen Deciduaabschnittes war wahrscheinlich bedingt durch die ödematöse Durchtränkung desselben.

Journ.-Nr. 35. Frau Koch, 34 Jahre alt, XI para, acht normale Geburten, zwei Aborte vorhergegangen. Letzte Regel vor drei Monaten. Seit einigen Stunden starke Blutung. Temperatur nicht erhöht, Puls fadenförmig, häufige Ohnmachten, Ohrensausen u. s. w. Scheide von Blutgerinnseln förmlich anfgebläht.

Das Ei steckt in dem erweiterten Cervicalkanale und setzt sich mittels eines strangartigen Gebildes in das Uteruscavum fort. Nach oben zu verbreitert sich der Strang und scheint ungefähr in der Mitte des Uteruscavum ringsherum an der Uteruswand zu inseriren. Leichter Druck auf den Eisack bringt ihn zum Platzen, befördert abex zu gleicher Zeit das Ei mit der ganzen Decidua vera heraus. Das darauf vorgenommene Cürettement ergiebt nur minimale Gewebsbröckel.

Lauwarme Eingiessung in den Mastdarm, Niedriglagerung des Kopfes, Excitantien. Weiterer Verlauf gut.

\section{Mikroskopischer Befund:}

Schnitt $4 \mathrm{~mm}$, Zellschicht 0,5 mm, Drüsenschicht 3,5 $\mathrm{mm}$ dick. In der Zellschicht zahlreiche typische. Deciduazellen, Rundzellen weniger zahlreich. Die alveoläre Schicht zerfällt wieder in zwei Schichten: In der oberflächlicheren, an die Zellschicht anstossenden Schicht bilden die Drüsen senkrecht stehende, bis zu $2 \mathrm{~mm}$ lange, $0,5 \mathrm{~mm}$ breite Räume. Stellenweise findet sich nur eine einzige solche Lage, theilweise aber drei Lagen, deren Drüsen kleiner sind als die nur in einer Lage angeordneten Drüsen. Dann 
folgt die tiefere Schicht mit der Oberfläche parallelen Drüsenräumen, die bis zu fünf Reihen übereinander liegen und schmälere Septa zwischen sich lassen. In diesen tieferen Drüsen findet sich der Epithelsaum vielfach erhalten. Starke Gefässentwickelung, keine Extravasation.

Aus den geschilderten mikroskopischen Befunden glaube ich, um es noch einmal zusammenzufassen, folgende Schlüsse ziehen zu dürfen:

1) Bei Aborten Iöst die Cürette die Vera in derselben Schicht, in welcher bei spontanem Verlaufe die Abtrennung von der Uteruswand geschieht.

2) Die Loslösung findet in der tiefen, nicht, wie Langhans annimmt, in der oberflächlichen alveolären Schicht statt.

Betrachtet man die Schnitte von Leopold ${ }^{1}$ ), welche durch die ganze Decidua und die Uterusmuskulatur gelegt sind und von Abortfällen des zweiten und vierten Monates herrühren, so sieht man, dass hier die Drüsenräume in fünf bis acht Schichten übereinander liegen. Dasselbe ist der Fall bei den ron mir untersuchten Deciduapräparaten. Dieselben stimmen überhaupt so vollständig mit den Le opold'schen Abbildungen überein, dass zu der völligen Gleichheit meinen Schnitten eben nur die Uterusmuskulatur fehlt.

Es ist ferner eine von Düvelius²) festgestellte Thatsache, dass das Cürettement die Schleimhaut des nicht schwangeren Uterus so vollständig entfernt, dass nur die in der Uterusmuskulatur steckenden blinden Drüsenendigungen zurückbleiben. Der Schluss ist wohl nicht zu gewagt, dass die Cürette die weichere Decidua vera ebenso vollständig von der Uterusmuskulatur ablösen wird. In derselben Tiefe trennt sich auch bei spontanem Verlaufe des Abortus die Decidua ab. Der Beweis liegt in der völligen Gleichheit der mikroskopischen Bilder von Decidua, die spontan ausgestossen, und solcher, die durch Cürettement entfernt worden ist, sowie in der Thatsache, dass das, nach völliger, nicht durch Cürettement, sondern durch leichten Druck auf den Eisack bewirkter Ausstossung der Decidua vera, ausgeführte Cürettement nur noch ganz minimale Gewebstrümmer aus dem Uterus herausbringt.

1) 1. c.

2) I. c. 
3) So lange Decidua vera und reflexa nicht mit einander verwachsen sind, wird durch die Wehen nur die Placentaranlage von der Uteruswand abgelöst. Der alsdann nach unten sinkende Eisack zerrt mechanisch die Decidua veravon der Uteruswand los.

4) Dieser Vorgang ist indessen ein unvollkommener, da oft fester haftende Stücke der Decidua abreissen und im Uterus zurückbleiben.

ad 3) Abgesehen davon, dass man, so lange die Placenta noch adhärirt, niemals auch nur ein Stïck der Decidua vera gelöst findet, kann man sich durch Betrachtung eines exstirpirten schwangeren Uterus sehr leicht davon überzeugen, dass es den Wehen unmöglich ist, die Decidua vera primär abzulösen. Mir bot sich kürzlich diese Gelegenheit dadurch, dass Herr Gusserow einen in der vierten bis fünften Woche schwangeren Uterus wegen Carcinom mittels der Totalexstirpation entfernte. Hier stellte die ungefähr $0,5 \mathrm{~cm}$ dicke Vera eine zitternde Gallerte dar, die sich bei dem geringsten Anstosse wellenförmig auf ihrer Unterlage verschob. Verkürzt sich also die Uteruswand durch die Wehenthätigkeit, so faltet sich die Decidua vera: die langen dünnen Septa der tiefen Drüsenschicht gestatten ihr eben grössere Excursionen, machen also eine primäre Ablösung derselben durch die Wehen unmöglich. Ich kann mir eine solche nur dann zu Stande kommen denken, wenn entweder die Vera durch Blutcoagula mit der Reflexa verfilzt ist oder selbst durch massige Extravasate stark verdickt, unnachgiebig geworden ist. Mir ist ein solcher Fall nie vorgekommen. In der auf Dohrn's Veranlassung verfassten Dissertation von Franz: „Ueber Blutextravasate in Abortiveiern" finden sich zwei Abbildungen, in welchen die Decidua vera allseitig der Decidua reflexa anliegt. Hier hat sich also wahrscheinlich bei Beginn der Wehenthätigkeit die Decidua vera zuerst, und zwar von unten nach oben gelöst. Hier heisst es aber auch in der Beşchreibung: Die Decidua vera lässt sich stellenweise von der darunterliegenden Reflexa abheben; und: die ganze Masse ist so compact und fleischähnlich, dass die Bezeichnung als Fleischmole geeignet erscheint.

ad 4) Die mechanische Lostrennung der Decidua vera wird vielleicht durch in den tiefsten Lagen der Drüsenschicht vorhandene Blutextravasate begünstigt. Dass aber die Lostrennung auch ohne sie geschehen kann, beweist Fall Birghan: Hier fanden 
sich in der spontan ausgestossenen Decidua vera nur vereinzelte Blutextravasate, und diese lagen in der Zellschicht. Vielleicht spielt auch die Consistenz der Decidua vera eine Rolle bei der Ablösung. In Fall Röhl wenigstens war der spontan losgelöste Theil der Decidua vera von auffallend sulziger Beschaffenheit. Da aber ein Zusammenwirken von all diesen, die exacte Loslösung begünstigenden Momenten wohl nur selten statthat, so finden wir eben so häufig bei spontan verlaufenem Abort eine Retention von Theilen der Decidua vera. Was für Consequenzen die Therapie aus diesem Umstande $z u$ ziehen hat, ist oben schon zur Genüge auseinandergesetzt worden.

Was nun endlich die erzielten Heilungsresultate anlangt, so starben von den 120 Fällen, wie schon erwähnt, 2 (Fall 50 u. 576).

Ein Fall litt vier Wochen an einer Perimetritis (389), ein zweiter acht Tage an einer leichten Parametritis (81), ein dritter zwei Tage lang an übelriechendem Ausfluss und Fieber (117). Die übrigen 117 Fälle, selbst die als septische Aborte in meine Behandlung gekommen waren, machten ein durchaus glattes, fieberfreies Wochenbett durch.

Journ.-Nr. 50. Frau Jörger, 30 Jahre, VIII para, zwei Aborte vorausgegangen, Graviditas mensis IV, war schon früher in unserer gynäkologischen Poliklinik an einer linksseitigen Parametritis behandelt, die nach einem schweren Puerperalfieber zuriickgeblieben war. Nach Ausstossung der viermonatlichen Frucht erfolgte eine starke Blutung, ohne dass es dem Praktikanten möglich gewesen wäre, die Placenta za exprimiren. Ich schritt daher zur manuellen Lösung und schickte derselben eine intrauterine Ausspülung mit 3 proc. Carbolsäure voraus. $\mathrm{Zu}$ gleicher Zeit begann der Praktikant die Frau zu chloroformiren. Die Frau hatte zwei bis drei Athemzigge unter der Chloroformmaske gethan, und es mochten bei der Ausspülung vielleicht $100 \mathrm{~g}$ der Carbollösung in das Uteruscavum eingeströmt sein - der Abfluss war ein ungehinderter - , da hörte plötzlich die Athmung auf und der Puls wurde äusserst klein. Zugleich begann wieder eine starke Blutung aus der Gebärmutter. Da der Praktikant die künstliche Athmung nicht ordentlich machte, tamponirte ich rasch die Scheide mit Jodoformgaze und brachte nach einiger Zeit die Frau wieder zu spontanem Athmen. Alsdann löste ich die Placenta, eürettirte, da die Blutung nicht aufhörte, machte eben deswegen eine Ausspülung mit einfachem heissen Wasser und tamponirte, nachdem inzwischen auch Ergotininjectionen keine Wirkung zeigten, den Uterus mit der dem Praktikanten gehörenden Salicylwatte (meine Jodoformgaze hatte ich völlig zur Scheidentamponade verbraucht). Excitantien. 
Die zwei nächsten Tage war Patientin fieberfrei; der Puls war klein, 90 bis 110. Carbolurie. Am dritten Tage 38,6, Puls 110. Schmerzen in der linken Seite, leicht übelriechender Ausfluss. Uterus nur noch wenig vergrössert, Cervicalkanal geschlossen, im linken Parametrium eine harte, schmerzhafte Infiltration. Uterusausspiulung mit 0,3 proc. Salicylsäure.

Wegen ungünstiger äusserer Verhältnisse wird der Patientin die Aufnahme in die Charité empfohlen. Sie hatte anfangs diese $A b$ sicht, nahm sich aber dann einen Privatarzt und starb nach einigen Tagen.

Journ.-Nr. 576. Arbeitersfrau Gellner, 35 Jahre, IV para, drei normale Geburten. Seit acht Tagen Fieber und Blutung. Letzte Regel vor drei Monaten. Temperatur 40,6, Puls 120, klein. Collabirtes Aussehen. Uterus in Nabelhöhe, von prall elastischer Consistenz, Cervicalkanal völlig geschlossen, jauchiger Ausfluss aus der Gebärmutter. Bei den ersten Athemzügen Chloroform-Asphyxie; doch gelingt es, die Patientin wieder zu spontanem Athmen zu bringen, auch der Puls wird wieder fithlbar. Schwieriges Eindringen des Fingers in das Uteruscavum, Ausräumung desselben theils mit dem Finger, theils mit der Cürette; dabei Entweichen von Gasen aus dem Uterus, Blutverlust gering. Carbolausspülung (3 proc.), Excitantien, Aether. Eine Stunde nach beendeter Operation erfolgt der 'Tod.

Journ. -Nr. 389. Frau H., 30 Jahre alt, IX para, drei Aborte. Letzte Regel vor 21/2 Monaten. Von anderer Seite ist schon mehrere Tage wegen der Blutung tamponirt und Dower'sche Pulver gegeben worden in der Meinung, dass das $\mathrm{Ei}$ noch im Uterus sei. Das Cürettement fördert nur kleine Deciduafetzen zu Tage. Auffallende Druckempfindlichkeit des Uterus. Wegen Fiebers, perimetritischer Erscheinungen und ïbelriechenden Ausflusses wird Patientin in den nächsten Tagen in die Charité geschickt. Nach drei Wochen geheilt entlassen. Ich erfuhr später, dass die Frau auch diesmal wieder, wie in den früheren drei Aborten, den Abort nach Trinken eines Hopfenaufgusses durch Einführung eines Hakens in die Genitalien herbeigeführt habe. ${ }^{1}$ )

Journ.-Nr. 81. Musikerfrau Schulz, 28 Jahre, IIIpara, zwei normale Geburten. Schwangerschaft des vierten Monats. Die Eiblase, nur von Amnion und Chorion gebildet, liegt vor der Scheide und setzt sich nur durch einen dünnen Strang durch den für einen Finger durchgängigen Cervicalkanal in das Uteruscavum fort. In der unverletzten Fruchtblase, ebenfalls vor der Scheide, liegt der Fötus. Sprengung der Blase, Placenta nach vergeblichem Versuche, sie herauszudrehen, manuell entfernt. Dabei bleibt ein Placentarrest zurück, der auch durch die Cürette nicht gelöst wird, während letztere die Decidua in grossen Fetzen leicht herausschafft. Secale. Keine weitere

1) Vor mehreren Tagen hat die $\mathrm{H}$. wieder unter sehr verdächtigen Umständen im vierten Monat abortirt. 
Blutung, dagegen viertägiges Fieber bis 38,8 , linksseitiges parametritisches Exsudat, welches jedoch nach acht Tagen ganz wieder verschwunden ist.

Mikroskopischer Befund der herausgeschabten Decidua:

Schnitt $1 \mathrm{~mm}$ breit. Starker Gefässreichthum, aber geringe Extravasationen. Wenig typische Deciduazellen. Deutliche Trennung in Zell- und Drüsenschicht. Beide Schichten von gleicher Dicke. Die Drüsen, die in mehreren Schichten übereinander liegen, bilden der Länge des Schnittes folgende, schmale, lange Spalten.

Journ.-Nr. 117. Frau Grosser, 34 Jahre alt, VII para, sechs normale Geburten. Schwangerschaft des vierten Monates. Nach isolirter Ausstossung der Frucht profuse Blutung. Temperatur 36,4, Puls sehr klein, hochgradige Anämie. Manuelle Lösung der Placenta, Cürettement. Uterusausspülung mit einfachem heissen Wasser. Am Abend des zweiten Tages Hitze; am Morgen des dritten 39,3, Nachmittags 38, 7 , Puls 138. Intrauterine Salicylsäureausspülung. Nächsten Tag und weiterhin fieberfrei.

Was die beiden Todesfälle anlangt, so war in Fall 576 von vornherein bei dem Befinden der Patientin jede Therapie hoffnungslos. Verschiedene Umstände machten es mir sehr wahrscheinlich, dass es sich hier um einen criminellen Abort handelte.

In Fall 50 wirkten eine ganze Reihe ungünstiger Momente zusammen: die chronische, nach einem schweren Puerperalfieber zurückgebliebene Parametritis, die bereits vorhandene Anämie, der Carbolzufall, die andauernde Atonie des Uterus und der Wechsel in der Behandlung. Letzteres Moment scheint mir das bedeutsamste; denn als ich die Patientin am dritten Tage zum letzten Male sah, war keine Spur von peritonitischen Erscheinungen vorhanden, nur wegen der besseren Pflege drang ich auf die Ueberführung in die Charité.

Den Carbolzufall habe ich sogar bei zwei dem dritten Monate angehörenden Abortfällen erlebt:

Journ.-Nr. 45. Frau Schleusener, 37 Jahre, IVpara, zwei normale Geburten, ein Abort vorausgegangen. Gravidität von $21 / 2 \mathrm{Mo}-$ naten. Zwei Stunden zuvor Ausstossung einer macerirten Frucht. Temperatur 38,5, Puls 100 . Uterus stark anteflectirt, faustgross, innerer Muttermund völlig gesehlossen. Der Finger dringt allmälig ins Uteruscavum ein, entfernt einen Theil der Placenta, kleine Stücke 
bringt die Cuirette heraus, doch bleibt, weil der Finger nicht bis zur Wurzel eingeführt werden kann, immerhin noch ein Theil der Placenta im Fundus sitzen. Bei der intrauterinen 3 proc. Carbolsäureausspiilung Aufhören der Athmung und des Pulses. Rasche Wiederbelebung. Wegen Andauer der Blutung Uterustamponade. Am folgenden Tage ist Patientin fieberfrei. Mit den Jodoformgazestreifen werden zu gleicher Zeit Placentarreste entfernt. Urin ist schwarz und enthält etwas Eiweiss. Weiteres Befinden gut,

Journ.-Nr. 86. Frau Gohlke, 35 Jahre, XI para, acht normale Geburten, zwei Aborte vorausgegangen. Schwangerschaft des dritten Monats, seit vier Wochen Blutung, zwei Stunden vor unserer Ankunft Ausstossung einer dem zweiten Monate angehörenden macerirten Frucht. Bedeutende Anämie. Cervicalkanal völlig geschlossen. Das Cürettement entfernt die Decidua und kleine Placentarfetzen, Wöhrend der mittels des Fritseh'schen Katheters ausgeführten Uterusausspülung mit 3 proc. Carbolsäure Aufhören der Athmung und des Pulses. Längere künstliche Athmung, Aetherinjectionen u. s. w. erforderlich. Obgleich es nicht blutete, wird der Sicherheit halber bei der Anämie der Patientin die Scheide tamponirt (die Uterustamponade schente ich wegen der möglichen Jodoformintoxication). Infolge dessen folgten den nach zwölf Stunden herausgezogenen Gazestreifen ausser mehreren Placentastücken grosse Blutklumpen, welche den trotz Ergotin schlaff gebliebenen Uterus ausgefüllt hatten. Carbolurie. Weiteres Befinden bis zum fünften Tage gut, dann typischer Wechselfieberanfall: Es stellt sich heraus, dass Patientin an chronischer Malaria leidet. Die Fieberanfälle werden durch Chinin prompt beseitigt.

Die Carbolintoxication dieses Falles erklärte sich aus dem Umstande, dass das Abflussrohr des Katheters durch ein Placentastïck theilweise verstopft war. Dieselbe Aetiologie wird wohl auch der erste Fall gehabt haben, doch habe ich damals nicht weiter speciell auf dieselbe geachtet.

Zum Schlusse möchte ich noch auf eine grössere Statistik über die in unserer Poliklinik behandelten Aborte hinweisen. Dieselbe ist in einer Dissertation von Lechler') enthalten und umfasst 520 Fälle aus den Jahren 1880 bis 1883 . Von diesen wurde die Hälfte activ mit manueller Ausräumung beendet. Es starben drei Frauen an intercurrenten Erkrankungen, nur eine an den Folgen des Abortus.

1) Pathologie und Therapie des Abortus. 1883. Berliner Dissertation. 